\title{
Research on Ways of Technical and Skilled Talents Training
}

\author{
Liu Li \\ Wuhan Railway Vocational College of Technology \\ Wuhan China 430205 \\ meetingexpert@sina.com
}

\begin{abstract}
The training of technical and skilled talents for high-speed railway industry is designed to cultivate personnel with better practical skills, better thinking capacity and better growth potential for the construction, maintenance, management, operation service and other fields of high-speed railway. In this paper, the author introduces the basic quality requirements of high-speed railway technical and skilled talents, analyzes specific problems and basic principles of talent training in high-speed railway industry and offers some ways to train such kind of talents in the practice, hoping to present certain reference for technical and skilled talent training of high-speed railway industry
\end{abstract}

\section{Keywords—high-speed railway; skilled talent; way of training}

\section{INTRODUCTION}

In recent years, with the rapid development of China's highspeed railway industry, it has been featured by increasingly higher technical contents, longer operating mileage and more stringent security requirements, so that requirements for the comprehensive quality of technical and skilled personnel are becoming higher and higher. How to train all kinds of professional and technical talents who can meet the needs of high-speed railway development has become an important research topic of high-speed railway enterprises and railwayrelated higher vocational colleges.

\section{QUALITIES OF TECHNICAL AND SKILLED TALENTS REQUIRED BY HIGH SPEED RAILWAY}

\section{A. Knowledge quality}

High-speed railway is a professional rail transit while technical talents are main implementers engaging in technical work, so that they must have solid knowledge of professional basis, professional technologies and professional operation. And these basic skills are also the most basic requirements to engaging in related work. Of course, in addition to mastery of the most basic technical points, technical personnel should master some knowledge of technical management. At the same time, they must be able to continuously improve themselves combining with the actual practice and constantly sum up experience by linking theory with practice, so as to constantly improve the practical ability.

Key project of China Education Association for International Exchange(CEAIE)higher vocational college internationalization: Study on Higher Vocational Colleges ' International Talent Cultivation Mode ((project number:GJ2016-002)

\section{B. Capacity quality}

The ones with basic knowledge of operation can only be regarded as the technical personnel. To become skilled talents, they need to strengthen the multi-faceted study. Technical ability is the external performance or manifestation of technical knowledge and comprehensive quality, while the technical knowledge and overall quality can only be showed by technical talents in a variety of practical scenarios. It is not only a stable professional quality structure composed of technical laborers' professional knowledge, professional skills and working attitude, but is also the basis of concrete work like construction and operation of high-speed railway. The professional ability of technical and skilled talents covers many aspects shown as table 1 .

TABLE I. PROFESSIONAL ABILITY OF TECHNICAL AND SKILLED TALENTS

\begin{tabular}{|c|c|c|}
\hline \multicolumn{3}{|c|}{ Ability of technical and skilled talents } \\
\hline Professional ability & Gnosis & Professional ethics \\
\hline Technical ability & Presentation skills & Cooperative ability \\
\hline $\begin{array}{c}\text { Technical management } \\
\text { Equipment } \\
\text { maintenance }\end{array}$ & Social competence & Volitional quality \\
\hline Others & Production capacity & Health psychology \\
\hline
\end{tabular}

\section{Basic qualities}

Technical and skilled talents of high-speed railway industry generally work in the forefront of high-speed railway construction, operation and other fields. They often work in the form of a team, from production to construction and to services and management. Therefore, the basic quality mainly includes these aspects: first of all, they should have good ideological and moral quality; then, they should be highly dedicated and hard-working; in addition, they should have ability to cooperate with others and handle interpersonal relationships to ensure team harmony [1]. 


\section{PROBLEMS IN THE TECHNICAL AND SKILLED TALENT TRAINING FOR HIGH-SPEED RAILWAY INDUSTRY}

\section{A. The quantity and quality of talents cannot meet the demand of production}

At present, China's high-speed railway industry has a large team composed of technical and skilled personnel. However, to be evaluated with requirements of "talent", not all technical personnel can be called as technical and skilled talents. It can be seen from the detailed introduction above that technical and skilled talents must have highly comprehensive quality. At the same time, the rapid development of high-speed railway puts higher requirements for the quantity and quality of talents, which intensifies the shortage of technical and skilled talents. And meanwhile, in terms of capacity quality, the technical quality of current personnel is also good enough. Firstly, some technical workers do not master the latest knowledge and new skills timely, which may be attributed to that they do not have chances to participate in systematic training due to the training time or ways. Secondly, from the aspect of capacity appraisal, the appraisal system is still under construction and improvement and the nominal Senior Engineer may not meet actual corresponding requirements.

\section{B. Resource investment in talent training is insufficient}

Based on the training forementioned, the analysis in this part will also be conducted from two aspects. First of all, facilities for talent training are relatively old and the comprehensive training environment is bad. The practical training equipment in some training bases is also insufficient and it is difficult to carry out operational exercises. Secondly, teachers are relatively scarce. A large part of teaching is completed by part-time teachers, so that there is great extensible improving space in teaching methods, teaching techniques, teaching contents and other aspects. The lack of training resources, to a large extent, affects the improvement of talent qualities.

\section{Talent appraisal needs to be improved}

The ability appraisal of technical personnel is the main basis for the division of talents. But, the current technical appraisal system is still in perfecting and constructing, and the evaluation system and appraisal system of technical and skilled talents cannot meet needs of high-speed railway development. Firstly, in order to create a talent team which can satisfy related requirements as soon as possible, relevant departments, to a certain extent, focus on the quantity of talents while ignoring the quality in the process of appraisal. Secondly, in the respect of the evaluation mechanism, scientific indicators for assessment are shorted in the appraisal and management of technicians and senior technicians, which affects the quality of personnel identification to a certain extent. Last but not the least, the base for talent appraisal needs to be improved, too. It is necessary to strengthen the construction of third-party appraisal institutions to ensure the quality of the appraisal.

\section{Talent management needs to be perfected}

Talent management is important to the construction of skilled talent team. But, the posts and promotion system of skilled personnel of high-speed railway industry are not reasonable and scientific enough, and the selection and employment mechanism should be improved. Meanwhile, staff's salary also needs to be linked with their respective skill grade, so as to enhance their study enthusiasm. In addition, appointment procedures and standards in technical and skilled talents need to be further improved, in order to further enhance their influences in the general staff.

\section{BASIC PRINCIPLES OF TECHNICAL AND SKILLED TALENT TRAINING FOR HIGH-SPEED RAILWAY INDUSTRY}

To improve the quality of talents, it is necessary to develop the training plan of technical and skilled talents for high-speed railway industry. This is the essential foundation for achieving the goal of training advanced technical personnel and accomplishing training tasks. In the development process, it should follow some most basic principles to ensure the effectiveness of training plan, as shown followed.

\section{A. The principle of training talents for the future}

In recent years, with the rapid development of high-speed railway, new materials, new technologies and new processes used in high-speed railway construction are also in rapidly innovating and ever-changing. The modern science and technology development of high-speed railway is becoming increasing coordinated and comprehensive, and then gradually occupies the market with new technologies and equipment which are characterized by intellectualization and automation. This puts higher and more stringent requirements on the knowledge structure and operational capacity of advanced technical and skilled talents of high-speed railways. Therefore, the training of technical and skilled talents must advance with the times and update the concept, facing the future. Technical and skilled talents trained for high-speed railway industry should have the latest professional theoretical knowledge and operational skills as well as ability of self-learning and selfgrowth to meet the rapidly developing needs for talents [2].

\section{B. The principle of building effective teams;}

The technical and skilled talent is the backbone of the development of high-speed railway industry, and thus related training must be closely linked with requirements of highspeed railway development. The development of training courses should be combined with the basic requirements for the essential professional knowledge. Taking actual effects as ultimate goal, specific training must carry out teaching specifically under the guidance of the basic principle "correlating the theory with practice", so as to teach students in accordance with their needs and aptitude and highlight the comprehensive training of practical skills [3].

\section{The principle of cultivating comprehensive quality}

Technical and skilled talents of high-speed railway should have a well-rounded comprehensive quality. The fundamental difference between technical and skilled talents and general staff lies in their mastery of advanced expertise, more sophisticated skills and innovative skills. In addition, they need better physical and mental quality to cope with various 
pressures and respond to problems properly. Therefore, in the formulation of training plan of technical and skilled talents, it is necessary to proceed from the overall skill and training their ability of both practice and thought, so as to cultivate them as technical and skilled talents who are expert in one thing and good at many.

\section{TRAINING WAYS OF TECHNICAL AND SKILLED TALENT FOR CHINA'S HIGH-SPEED RAILWAY INDUSTRY}

\section{A. To work hand in hand with higher vocational colleges}

In recent years, vocational education develops vigorously in china. Especially since the reform and opening up, China's various sectors of vocational education have made rapid development and achieved remarkable results under the leadership and support of the relevant departments and active efforts of vocational education workers. They train generations of skilled personnel with strong practical ability for all walks of life. The high-speed railway industry needs a large number of operating-type technical personnel. To "customize" talents from the perspective of higher vocational education is bound to build a talent team meeting needs more quickly. Of course, to develop high-speed railway vocational education, the first thing is to change the traditional concept of education and reestablish the target of personnel training according to actual needs of the construction and operation of high-speed railway.

Vocational education cultivates a large number of talents for the whole society. But in the traditional view, the educational attainment of vocational school students is inferior to others and many people hold that they can only do routine work which is simple and repetitive. This is a mistake actually. The main difference between higher vocational colleges and ordinary colleges and universities is that their training objectives and their focuses on teaching and evaluation are different. In view of demands for high-speed railway technology, training of technical and skilled talents should try to reform the relevant professional and teaching contents to establish a new curriculum system and teaching system of technical personnel for high-speed railway industry, by combining general courses with special courses of high-speed railway. Moreover, it is also feasible to actively explore the cooperative mode of "production and study" with higher vocational colleges.

\section{B. To establish the key training system of technical and skilled talents for high-speed railway industry}

In 1996, China promulgated the Vocational Education Law, which clearly states: "enterprises should designedly apply education on their staff and the ones they are ready to employ according to the actual situation." As big scientific and technological companies, high-speed railway enterprises have many advantages in training technical and skilled talents: It have strong practical technical strength and more complete equipment as well as more abundant experience of educating technical and skilled workers; The application of technological innovation or technology research in high-speed railway enterprises can become the great incentive promoting the growth of technical and skilled talents. For most skilled personnel, working in environment full of changes can stimulate their ability and wisdom, cultivate their volition and enhance their competence, improving their comprehensive ability.

\section{To explore the growth incentive mechanism of technical and skilled talents for high-speed railway industry}

High-speed railway enterprises can try to establish and improve the legal system of technical and skilled talent training to constantly strengthen the legal management. Based on the Law of Education, Labor Law, Vocational Education Law, Regulation on the Administration of Running of Schools by Non-Governmental Sectors and other laws, they can formulate specific implementation approaches more suitable for highspeed railway enterprises and develop incentives more matching, in order to cultivate more new technical and skilled talents more rapidly. At the same time, they can try to improve the selection mechanism for technical and skilled talents. For example, in the condition of the same technical and skill, young personnel who are under the age of 35 and have high ideological and technical quality can have the priority to be trained. More comprehensive assurance and strong support can be given to the specific training time, funding, level and channels. In terms of personnel appointment, enterprises should dare to let these young people undertake important tasks, give them opportunities to take charge of technical research and guide them to give full play to the role of technology and skill leader, so as to promote more growth.

\section{To publicize and establish models of technical and skilled talents in the enterprise}

Experience of some other areas can be drawn in this aspect. For example, the state has established a selection and recognition system "Chinese Skills Awards" and "National Technical Experts", which target the national skilled workers and take a number of outstanding skilled workers as the objects They have a good professional ethics and have mastered the superb operating skills. The entire selection is also based on strict selection criteria, selection ratio and review procedures. More importantly, these activities establish models by strengthening publicity to make winners have a sense of honor and participants have new goals, and meanwhile promote more technical and skilled personnel to actively learn and continuously improve their skills. High-speed railway enterprises can actually imitate this method. They can carry out some selection activities in the enterprise or in the whole industry and conduct multi-channel publicity, which can effectively promote the training of technical and skilled talents.

\section{E. To integrating the cultural construction of the high-speed railway enterprises with the talent training}

The combination of corporate culture and talent training should be processed from two aspects. On the one hand, highspeed railway enterprises need to cooperate with higher vocational colleges, giving full play to the aggregated advantage of "school-enterprise culture". It is necessary to combine the unique corporate culture of high speed railway enterprises with the idea of training talents in higher vocational colleges to enrich the cultural connotation of "school-enterprise cooperation". On the other hand, high-speed railway 
enterprises themselves should attach importance to the effective integration of culture and personnel training.

Here focuses on the "school-enterprise cooperation". In the process of technical and skilled talent training for high-speed railway industry, higher vocational colleges can introduce cultural contents of high-speed railway enterprises and form training concept of innovative talents, building vocational indepth cooperation model of higher vocational colleges and high-speed railway enterprises. These aspects can be carried forward specifically: firstly, in the process of technical and skilled talent training, higher vocational colleges should create a strong atmosphere of high-speed railway culture through a variety of ways; secondly, in the management of education and teaching, higher vocational colleges should actively introduce the management system of high-speed railway enterprises, so that students can accept the education of high-speed railway culture; thirdly, the special courses offered by higher vocational colleges should actively show the high-speed railway culture. In short, the effective integration of culture and education can make students or talents be unconsciously influenced and thereby cultivate more technical and skilled talents for the high-speed railway industry.

\section{CONCLUSION}

China's high-speed railway is known worldwide, for its world's longest high-speed railway operating mileage, the largest scale in construction and the world's leading overall technology level. It is a beautiful business card for China showing to the world. The comprehensive quality level of technical and skilled talents of high-speed railway has become the key quality index of talent training. Only constantly exploring and actively promoting the training level of technical and skilled talents can provide the most powerful talent support for China's high-speed railway industry to develop rapidly and maintain the leading position in the world in the future.

\section{REFERENCES}

[1] Fanju Kong, Approach to the Cultivation of Highly Skilled Personnel [J] China Adult Education, pp: 109-110, vol.16, 2007(1).

[2] Tianying Liu. The Inevitable Choice of Higher Vocational Education: "Double Certificate" System [J]. China Adult Education, pp: 110-111, vol.16, 2007(1).

[3] Wei Zhang. Discussion on Strengthening the Training of Highly Skilled Personnel of Railway [J]. Economic Research Guide, pp: 53-54. Vol.11, 2015(8). 